\title{
RADIATION EFFECTS ON OPTICAL COMPONENTS \\ OF A LASER RADAR SENSOR DESIGNED \\ FOR REMOTE METROLOGY IN ITER* ${ }^{*}$ CONF-97/065--
}

\author{
M. M. Menon, E. B. Grann, and A. Slotwinski ${ }^{\dagger}$ \\ Oak Ridge National Laboratory \\ P.O. Box 2008 \\ Oak Ridge, TN 37831-6305
}

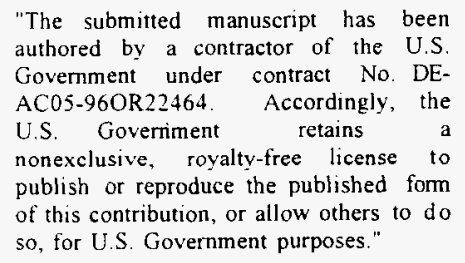

\section{8}

To be published in the Proceedings of the 1997 Symposium on Fusion Engineering, San Diego, California, October 6-10. 1997

DISTRISUTION OF THIS DOCLMENT is INIMITED Dh

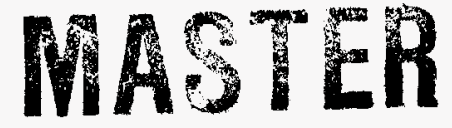

\footnotetext{
" Research sponsored by the Office of Fusion Energy Sciences, U.S. Department of Energy, under contract DE-AC05-96OR22464 with Oak Ridge National Laboratory, managed by Lockheed Martin Energy Research Corporation.

Coleman Research Corporation, Springfield, Va $22150-1808$.
} 


\section{DISCLAIMER}

This report was prepared as an account of work sponsored by an agency of the United States Government. Neither the United States Government nor any agency thereof, nor any of their employees, make any warranty, express or implied, or assumes any legal liability or responsibility for the accuracy, completeness, or usefulness of any information, apparatus, product, or process disclosed, or represents that its use would not infringe privately owned rights. Reference herein to any specific commercial product, process, or service by trade name, trademark, manufacturer, or otherwise does not necessarily constitute or imply its endorsement, recommendation, or favoring by the United States Government or any agency thereof. The views and opinions of authors expressed herein do not necessarily state or reflect those of the United States Government or any agency thereof. 


\title{
Radiation Effects on Optical Components of a Laser Radar Sensor Designed for Remote Metrology in ITER*
}

\author{
M. M. Menon ${ }^{a}$, E. B. Grann ${ }^{a}$, and A. Slotwinski ${ }^{b}$ \\ "Oak Ridge National Laboratory, Oak Ridge, TN 37831-6305 \\ ${ }^{h}$ Coleman Research Corporation, Springfield. VA 22150-1808
}

\begin{abstract}
A frequency modulated laser radar is being developed for in-vessel metrology and viewing of plasma-facing surfaces. Some optical components of this sensor must withstand intense gamma radiation $\left(3 \times 10^{6} \mathrm{rad} / \mathrm{h}\right)$ during operation. We have tested the effect of radiation on a silica core polarization maintaining optical fiber and on $\mathrm{TeO}_{2}$ crystals at doses up to $\sim 10^{y}$ rad. Additional tests are planned for evaluating the performance of a complete acousto-optic (AO) scanning device. The progress made in these tests is also described.
\end{abstract}

\section{I INTRODUCTION}

A frequency modulated coherent laser radar (CLR) system is being designed [1] for metrology and viewing of plasmafacing components in the International Thermonuclear Experimental Reactor (ITER). Soon after the fusion reactor begins operation, because of neutron activation of the reactor wall, the gamma radiation level inside the reactor will remain very high (estimated to be $3 \times 10^{6} \mathrm{rad} / \mathrm{h}$, a day after shutdown). Each metrology campaign in the ITER could last for times on the order of tens of hours. Because several such campaigns are anticipated during the life of ITER, radiation hardness in the $10^{8}-10^{9} \mathrm{rad}$ level is required of the metrology sensor components. Experimental information on radiation effects on components at such a high dose level is very sparse, particularly for some of the special optical components required for the ITER CLR metrology system. For the metrology device, two crucial components that required radiation testing were the acusto-optic ( $\mathrm{AO}$ ) beam deflector and the polarization maintaining (PM) optical fiber. The AO device utilizes diffraction of light by sound waves and has the potential for fast scanning of the laser beam; the PM fiber is required for transporting the beam. The heart of the $\mathrm{AO}$ beam deflector is a $\mathrm{TeO}_{2}$ crystal, which has a large diffraction figure of merit.

Published results on radiation effects on PM fibers [2-4] are disparate and mostly cover radiation levels below $10^{\mathrm{h}} \mathrm{rad}$. Marrone et al. [5] examined the effects of radiation in: hoth optical loss and PM ability of a Corning $0.85 \mu \mathrm{m}$ PM liber. The loss increased with dose, while the polarization parameter was unaffected. Although pure silica core fibers are known to have high radiation resistivity, $\mathrm{F}$ doped $\mathrm{OH}$ free cores are shown to improve the radiation resistance [6]. No known published information is available on radiation effects on $\mathrm{AO}$ devices.

\section{EXPERIMENTAL CONFIGURATION}

The gamma irradiation facility associated with the High Flux Isotope Reactor (HFIR) at Oak Ridge National Laboratory is used for the experiments. Specimens can be placed through an S-shaped tube in proximity with the spent-fuel rod stored in the reactor pool. The bottom end of the tube is placed adjacent to the spent-fuel rod, while the mouth of the tube protrudes above the reactor pool water level (Fig. 1).

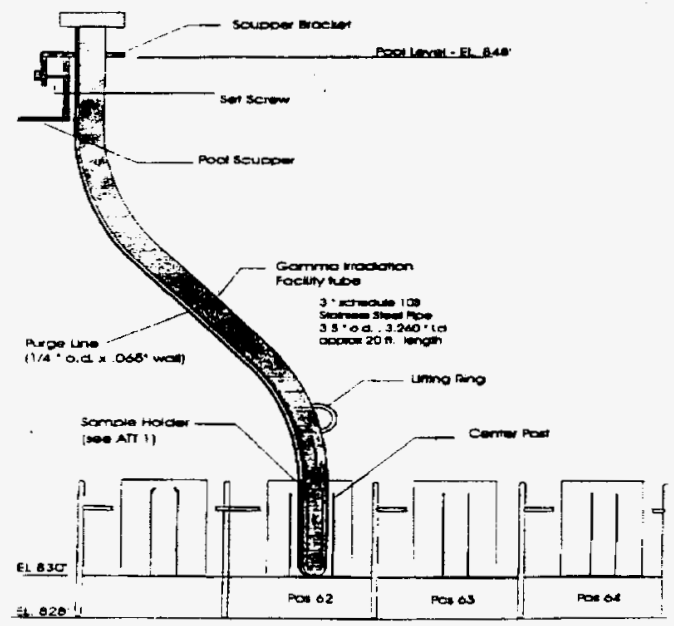

Fig. 1. The Gamma Irradiation Facility.

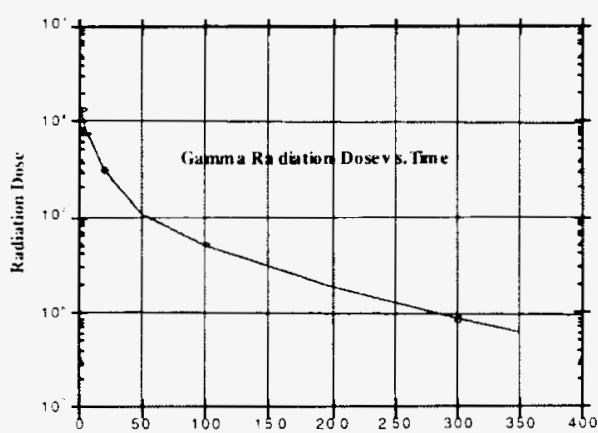

Parind ter S bualow n

Fig. 2. Gamma Dose Decay Characteristic.

\footnotetext{
"Research sponsored by the Office of Fusion Energy Sciences. U.S. Department of Energy. under contract DE-AC05-96OR22464 with Oak Ridge National Laboratory, managed by Lockheed Martin Energy Research Corporation.
} 
The gamma dose near the spent-fuel rod. 24 hours after it is removed from the reactor, is typically about $2 \times 10^{8} \mathrm{rad} / \mathrm{h}$, decaying with time as shown in Fig. 2. The energy spectrum of the gamma radiation from the HFIR spent-fuel rods is Maxwellian, with an average energy of $\sim 1 \mathrm{MeV}$ (Fig. 3). This is roughly similar to the gamma energy spectrum anticipated in ITER.

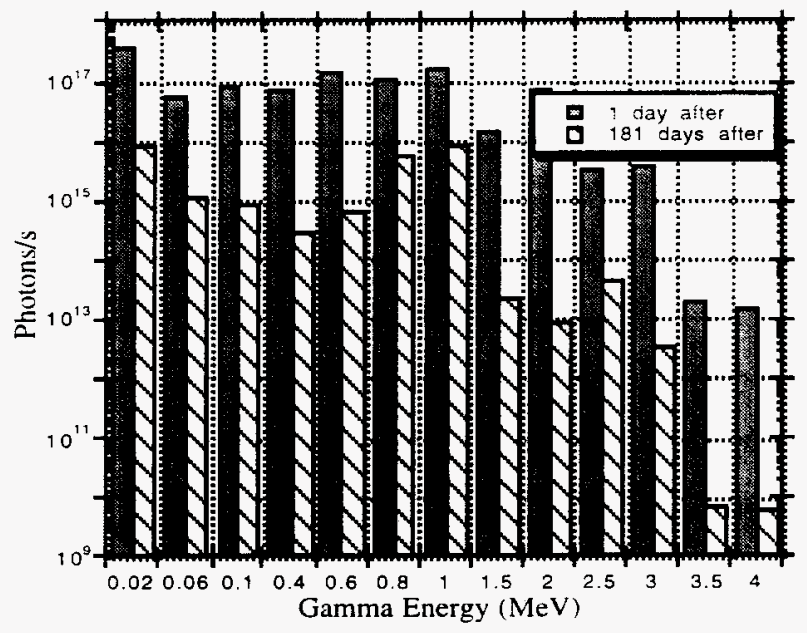

Fig. 3. Gamma Energy Spectrum.

A tetragonal form of $\mathrm{TeO}_{2}$ crystal $\left(1 \mathrm{~cm}^{3}\right)$. similar to the one planned for use in the AO beam deflector. was placed inside the specimen holder and lowered through the S-tube for irradiation. The arrangement shown in Fig. 4 was used for irradiating the PM optical fiber,. In this configuration. $\sim 60 \mathrm{~m}$ of PM fiber was used; $10 \mathrm{~m}$ from the midsection was wrapped around an aluminum mandrel with a diameter of $25.4 \mathrm{~mm}$ and placed in the test chamber, as shown schematically in Fig. 4.

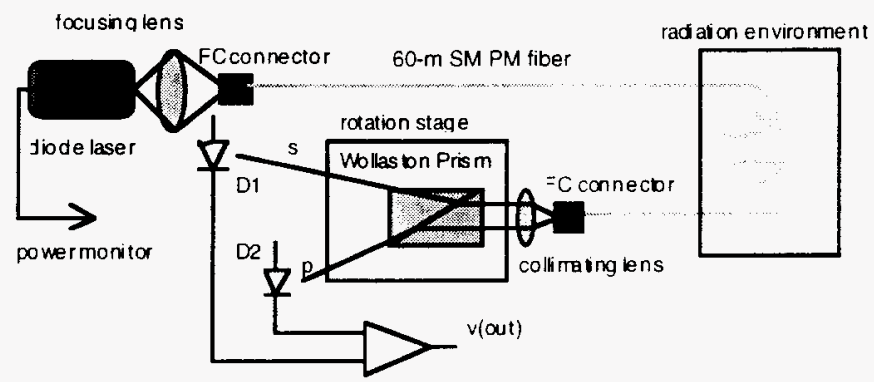

Fig. 4. Configuration for Testing PM Fiber.

A diode source providing a 1550-nm wavelength laser beam was coupled to one end of the fiber using appropriate PM connectors. The laser beam emerging from the other end was collimated and split into the two polarization components using a Wollaston prism. The magnitudes of the power in the two components of the beam were measured as a function radiation dose. Attenuation as well as changes in polarization could be measured in this manner. Although provisions were made for computerized data acquisition, this automatic data collection system malfunctioned. Therefore, the data points were manually collected by entering the reactor zone periodically.

\section{EXPERIMENTAL RESULTS}

\section{A. Tellurium Oxide Crystal}

Prior to irradiation, the lattice parameters of the $\mathrm{TeO}_{2}$ crystal were characterized by $x$-ray diffraction. The results: $\mathrm{a}=4.809 \pm 0.001 \AA \quad \mathrm{b}=4.809 \pm 0.001 \AA$ and $c=7.612 \pm 0.003 \AA$, were in agreement with published standards on this material. The measurements were then repeated after irradiating the crystal to a total gamma dose of $5.9 \times 10^{8} \mathrm{rad}\left(\right.$ at a rate of $2.2 \times 10^{6} \mathrm{rad} / \mathrm{h}$ ). There was no measurable change in any of the lattice parameters.

The transmission through the crystal as a function of wavelength, in the range of $800-2000 \mathrm{~nm}$, was measured using an IR spectrometer, both before and after irradiation. The results are shown in Fig. 5. No noticeable change was found in transmission characteristics due to irradiation, although "browning" of the crystal was evident.

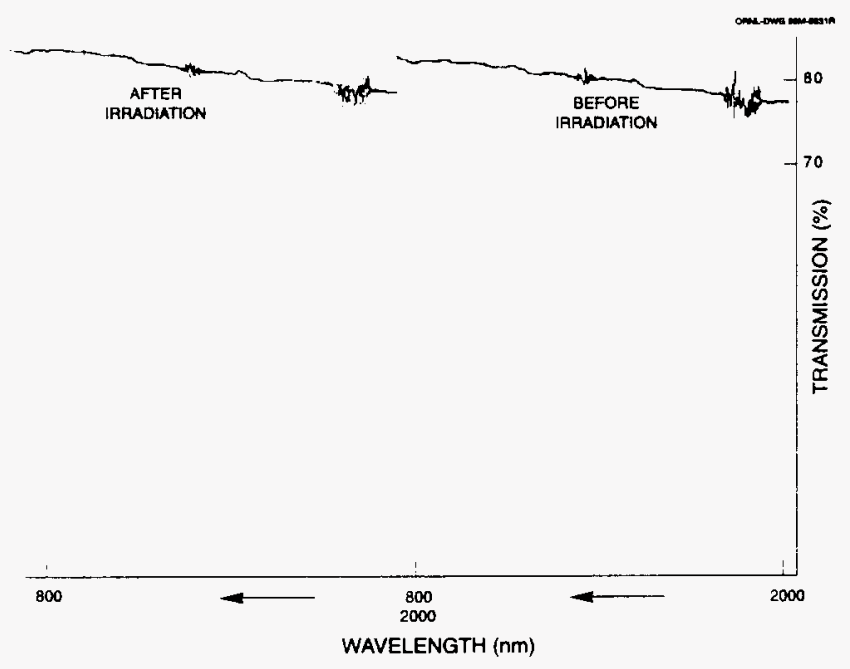

Fig. 5. Light Transmission Through $\mathrm{TeO}_{2}$.

In conjunction with the irradiation of the PM fiber (described in the next section), a second sample was introduced into the test cell. This sample was irradiated to a higher dose $\left(-10^{\prime \prime}\right.$ rad), and as in the first sample, the transmission characteristics were not affected. 


\section{B. Polarization Maintaining Fiber}

The Fujikura Panda fiber (SM.15-P-8/125.UV/UV-400) had silica core with UV-cured resin cladding. No other protective jackets were used. The fiber was irradiated to an aggregated dose of $1.4 \times 10^{y} \mathrm{rad}$ at a rate of $3 \times 10^{7} \mathrm{rad} / \mathrm{h}$. The PIN diode used to measure the e-component of the polarized light ceased functioning a few minutes after it was set up. This was replaced with a different type (with no collimating lens), but because it did not have sufficient sensitivity, measurement of the e-polarization component was not very reliable. However, within the uncertainty of the signal, the o- and e-components varied, maintaining the same ratio. Thus, irradiation had no noticeable effect on the polarization of the PM fiber. This conclusion was subsequently verified in the laboratory by comparing the two polarization components of an irradiated length of the fiber to those of a nonirradiated length.

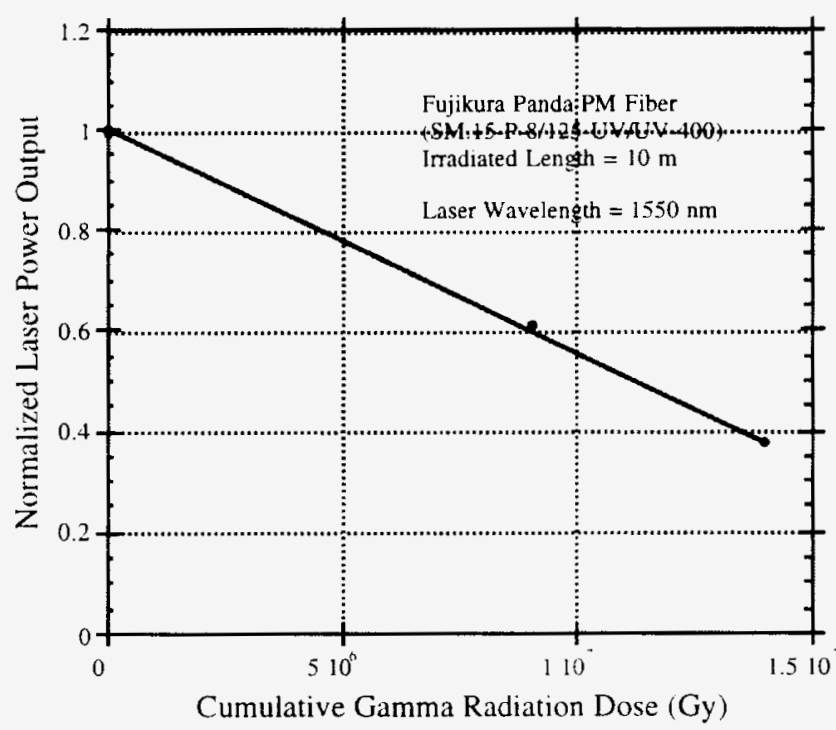

Fig. 6. Laser Transmission vs Radiation Dose.

The irradiation affected the laser transmission in the manner shown in Fig. 6. The measured attenuation for the $10-\mathrm{m}$ irradiated length of the fiber, at a cumulative dose of $1.4 \times 10^{9} \mathrm{rad}$, was $38 \%$. The radiation produced significant discoloration in the cladding material. but the core material was not visibly affected. There was some tlaking of the cladding at the midportion of the sample. where the radiation dose was the highest (the radiation dose varies along the length of the sample, peaking at the center and falling off on either end), but the core of the fiber was not visibly changed. In addition. the bending characteristics were not affected. Figure 7 illustrates the cladding damage, and Fig. 8 shows that the fiber could be bent to the minimum suggested diameter even after irradiation $1 \sim 25 \mathrm{~mm}$ bending diameter)

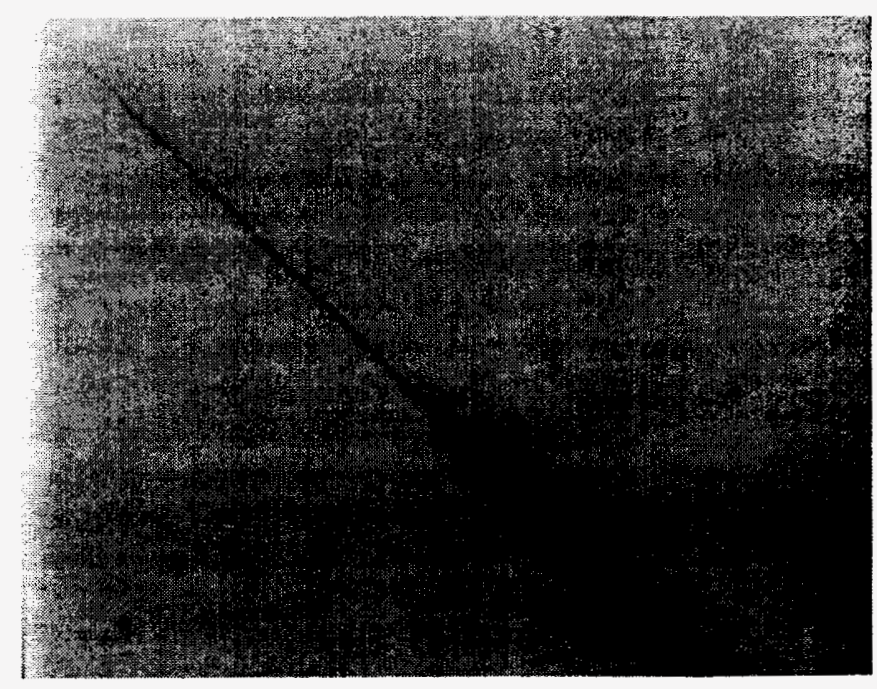

Fig. 7. Radiation Damage to the Fiber Cladding.

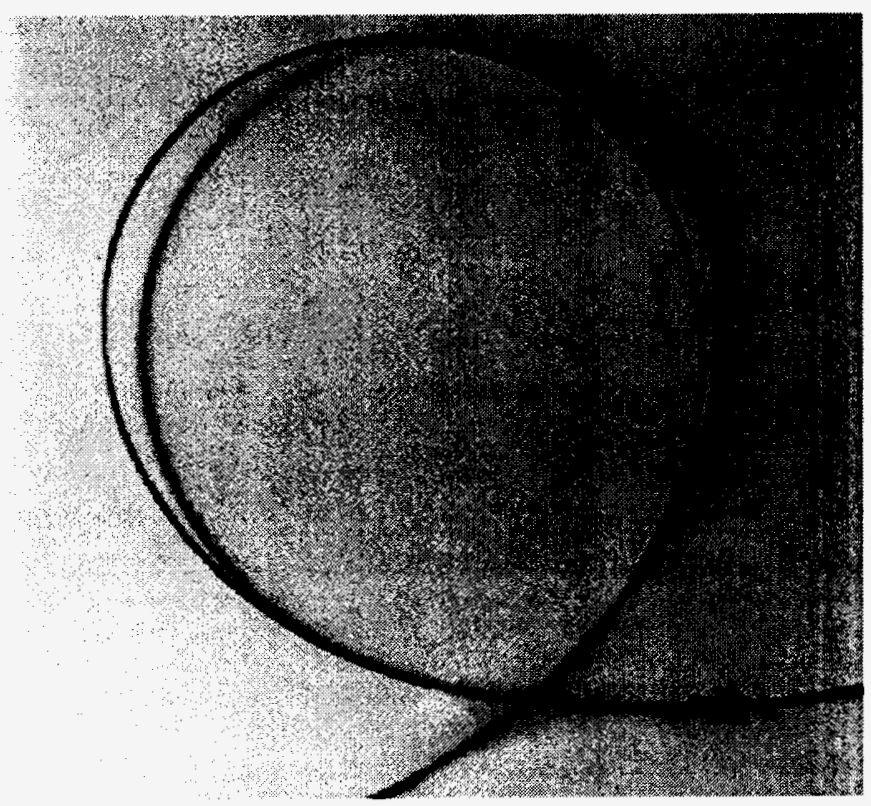

Fig. 8. Irradiated Fiber Bent at 25-mm diameter.

\section{FUTURE PLANS}

Although the $\mathrm{TeO}_{2}$ crystal exhibited very high radiation tolerance for the IR laser beam transmission, it is necessary to verify the complete operation of the $\mathrm{AO}$ device in the radiation environment. A dynamic test is planned wherein the beam deflection through the device will be monitored as a function of irradiation level. The experimental arrangement for this test, shown in Fig. 9, is currently being assembled. The experiment will consist of sending a laser signal through the AO device that is driven at the appropriate level, reflecting the deflected beam back to the fiber. and monitoring the signal level of this component with the help of a fiber coupler and a PIN diode. 


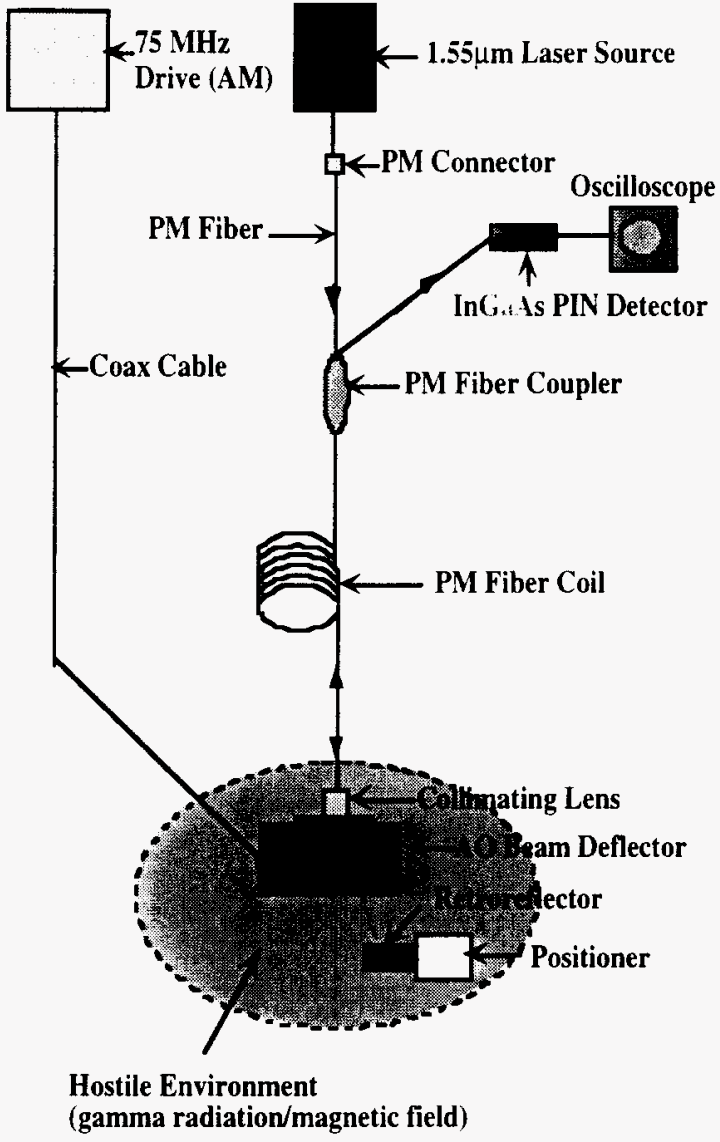

Fig. 9. Experimental Plan for Testing the AO Device.

\section{SUMMARY OF RESULTS AND DISCUSSION}

1) Light transmission through a single $\mathrm{TeO}_{2}$ crystal, in the wavelength range of $800-2000 \mathrm{~nm}$, was not affected by irradiation at doses up to $10^{9} \mathrm{rad}$.

It is known that absorption of radiation energy increases the formation of color centers [7]. Color centers are formed first in the UV band, and they gradually move toward the IR band as the radiation absorption is increased. This explains why the transmission through the $\mathrm{TeO}_{2}$ crystal was not affected in the IR band, although there was noticeable browning of the crystal. Note that the wavelength of interest for the CLR operation is in the IR band $(1550 \mathrm{~nm})$.

2) The PM characteristic of the fiber was not affected by radiation at levels up to $\sim 10^{y} \mathrm{rad}$.

The PM characteristic in the fiber is obtained by introducing stress-inducing rods that produce high birefringence (i.e., difference in propagation constant of light in two perpendicular polarizations). The asymmetric stress inherent in PM fibers is believed to reduce the effect of radiationinduced changes in PM ability [2].

3) There was a steady increase in attenuation with an increase in radiation, reaching significant attenuation levels $(38 \%$ for the $10-\mathrm{m}$ irradiated length) at a dose of $1.4 \times 10^{4} \mathrm{rad}$. However, this amount of attenuation can be tolerated by the CLR system, because the technique relies only on frequency measurement and not on amplitude (the amplitude affects only the signal-to-noise ratio).

The trend is consistent with published results at lower radiation fields. The magnitude of attenuation is known to be material and wavelength dependent.

\section{ACKNOWLEDGMENTS}

The authors acknowledge guidance received from Dr. Bruce Bernacki in designing the experiment, and of Dr. John Budai in conducting the $\mathrm{x}$-ray diffraction analysis of the $\mathrm{TeO}_{2}$ crystal. The authors are also indebted to Mr. Randy Hobbs for coordinating the experiment at the HFIR facility.

\section{REFERENCES}

[1] P. T. Spampinato, R. E. Bary, J. B. Chesser, M. M. Menon, M. A. Dagher, and A. Slotwinski, "A Laser Metrology/ Viewing System for ITER In-vessel Inspection," this meeting.

[2] E. J. Friebele, L. A. Brambani, M. E. Gingerich, S. J. Hickey, and J. R. Onstott, "Radiation Induced Attenuation in Polarization Maintaining Fibers: Low Dose Rate Response, Stress, and Materials Effects," Appl. Opt., Vol. 28, pp. 5138-5143, 1989.

[3] L. A. Brambani, E. J. Frieble, C. G. Askins, and M. E. Gingerich, "Radiation Effects in Polarization Maintaining Fibers," Proc. Soc. Photo-Opt. Instrum. Eng. Vol. 992, pp. 43-49, 1988.

[4] E. W. Taylor, V. R. Wilson, M. L. Vigil, R. A. Lemire. and E. E. Thompson, "Ionization Induced Nonequi ...ent Absorption in a Birefringent Silica Fiber," IEEE Phot. Tech. Lett.. Vol. 1, pp. 248-249, 1989.

[5] M. J. Marrone, S. C. Rashleigh, E. J. Friebele, and K. J. Long, "Radiation Induced Effects in a Highly Birefringent Fiber," Electron. Lett. Vol. 20. pp. 193-194, 1984.

[6] S. Okamoto, T. Ohinishi, T. Kanazawa, Y. Tsujii. H. Hayami. T. Zushi, and T. Akutsu, "Radiation Resistivity of Pure Silica Core Image Guides Under Intermittent Irradiation Tests," Bull. of Univ. of Osaka Prefecture. Vol. 42, pp. 109-121, 1993.

[7] P. W. Levy, "Overview of Nuclear Radiation Damage Process: Phenomenological Features of Radiation Damage in Crystals and Glasses." SPIE, Vol. 541. pp. 2-24, 1985. 


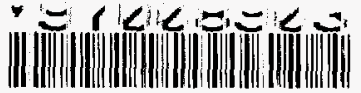

Report Number (14) ORNL/CP- 94834 CONF $971065-$

Publ. Date (11) 199709

Sponsor Code (18) DOELER, XF UC Category (19) UC-400, DOE/ER 